\title{
CONTRIBUIÇÕES E JUSTIÇA TRIBUTÁRIA NA ORDEM JURIIDICA BRASILEIRA
}

\section{NATÉRCIA SAMPAIO SIQUEIRA}

Mestre em Direito Tributário pela Universidade Federal de Minas Gerais. Professora de Direito Tributário na FA7. Procuradora do Município de Fortaleza. Advogada. naterciasiqueira@yahoo.com.br

Sumário: 1. Introdução; 2. Aspectos gerais da natureza jurídica da contribuição; 3 . Os fatos geradores das tradicionais espécies tributárias; 4. Modelos de tributação; 5. A contribuição como modelo de tributação; 6. A igualdade no custeio do Estado; 7. A adequação da contribuição ao justo modelo de custeio do Estado; 8. Tópicos conclusivos.

Resumo: O presente artigo trata das contribuições - espécie tributária - no ordenamento brasileiro. Nele, retoma-se às discussões referentes à natureza jurídica das contribuições; não apenas no tocante à sua natureza tributária ou de espécie autônoma, mas, fundamentalmente, em relação à adequação da tributação por contribuição ao sistema constitucional tributário. Desta forma, extraindo-se o modelo da tributação justo e racional, posto que em consonância com as liberdades fundamentais, os postulados da ordem econômica e a igualdade na distribuição da carga tributária, passa-se a estudar as contribuições, de modo que elas sejam criadas, reguladas e instituídas em adequação ao referido modelo de exação fiscal.

Palavras-chave: Contribuição. Adequação. Justo modelo constitucional de tributação. 


\section{InTRODUÇão}

O presente artigo enfoca questões referentes às contribuições, a partir dos possíveis modelos de tributação, admitidos no ordenamento jurídico brasileiro.

AConstituição em vigor, quando disciplina as contribuições, não raro se abstém de traçar-lhe os fatos geradores, limitando-se a estipular a aplicação de alguns princípios e das normas gerais tributárias ao regime jurídico das contribuições. Em razão de tal caráter normativo, tem-se uma permissividade absolutamente inadequada em relação às contribuições, o que gera a necessidade de traçar-lhes, com cuidado, os fatos geradores que podem apresentar, assim como os limites para a sua própria instituição.

Neste tocante, faz-se crucial a proposta de um modelo de tributação que seja justo e razoável ao Estado brasileiro, organizado como um estado Democrático e Social de Direito. É este o momento de enfocar-se como deve ser realizado o custeio dos gastos estatais, de forma que a carga tributária seja distribuída igualmente entre a coletividade e que a instituição dos tributos seja efetuada em conformidade com o conceito-chave do "mínimo existencial", que decorre do sistema de direitos fundamentais e com os princípios da ordem econômica.

Ou seja, o estudo referente à distribuição isonômica dos custos do Estado e ao equilíbrio entre o dever social de pagar tributos e os direitos fundamentais, aponta para um modelo de tributação justo e razoável, ao qual se devem conformar as contribuições.

\section{ASPECTOS GERAIS DA NATUREZA JURÍDICA DA CONTRIBUIÇÃO}

Não era pacífica a natureza jurídica das contribuições. A Constituição Federal de 05.10.1988 teve o mérito de assentar-lhe o caráter tributário. Veja-se: os artigos 149 e 149-A, referentes às contribuições, estão inseridos no capítulo que trata do Sistema Tributário Nacional; é certo que referidos dispositivos não encerram a disciplina constitucional das contribuições, mas trazem a regra de competência, além de determinar-lhe a aplicação de princípios constitucionais tributários e das normas gerais sobre a matéria tributária.

Entretanto, as dúvidas permanecem. Pode-se citar o debate acerca da autonomia das contribuições como espécie tributária, assim como as discussões referentes à sua estrutura.

No tocante ao primeiro conflito, o caput do art. $4^{\circ}$. do CTN dispõe que a natureza específica do tributo é determinada pelo fato gerador da respectiva obrigação, ainda estipulando, em seus incisos I e II, que a denominação, que as características formais adotadas pela lei e que a destinação do produto da arrecadação são irrelevantes para a determinação da espécie tributária. $\mathrm{O}$ art. $5^{\circ}$., por sua vez, complementa o dispositivo anterior ao afirmar que os tributos são impostos, taxas ou contribuições de melhoria. 
De posse de referidos dispositivos legais, a doutrina dividiu-se acerca da autonomia das contribuições como espécie tributária, entre os que não a admitiam ${ }^{1} \mathrm{e}$ os que a admitiam. Mas o fato é que, mesmo não se admitindo a autonomia da contribuição como espécie tributária, é certo que a destinação foi fator determinante ao Constituinte para particularizar o regime jurídico das contribuições, sem descaracterizar-lhe a natureza tributária.

Outrossim, perante o judiciário prevaleceu a tese de que a contribuição não é imposto, taxa ou contribuição de melhoria; antes, ela apresenta-se como espécie autônoma e com regime jurídico próprio - é o que se desprende dos julgados que não aplicam as imunidade às contribuições, quando as regras imunizatórias se restringem, no texto em que são vazadas, aos impostos.

Pensa-se, entretanto, que a polêmica delineada não pode levar ao extremo de superestimar a função da destinação e menosprezar o fato gerador - é o que está a ocorrer. Por outro lado, ainda não se tem um consenso quanto à estrutura da contribuição. Neste ponto, questiona-se se o fato gerador da contribuição reduz-se a um dos fatos geradores característicos das tradicionais espécies tributárias ou se apresenta estrutura própria. Igualmente, tem-se discutido acerca da necessidade de adequação entre a finalidade da contribuição e o contribuinte; se o contribuinte, de alguma forma, deve integrar o grupo beneficiário da atuação estatal custeada pelos recursos das contribuições.

Ambas as questões estão intricadas com análises, verdadeiramente, fundamentais do direito tributário, referentes à estrutura do modelo do custeio do Estado que seja justo, razoável e que reflita o equilíbrio entre os diversos interesses basilares que compõem o ordenamento jurídico.

\section{OS FATOS GERADORES DAS TRADICIONAIS ESPÉCIES TRIBUTÁRIAS}

Uma das questões referente à contribuição diz respeito ao seu fato gerador: se é próprio ou se subsume-se a algum dos característicos das tradicionais espécies tributárias os impostos, as taxas e as contribuições de melhoria.

Em relação ao fato gerador, é certo que ele, de forma isolada, não esgota o regime jurídico dos tributos; entretanto, ele reflete a relação de custeio existente entre o contribuinte e o Estado, sinalizando os princípios constitucionais a serem aplicados.

Melhor explicando, faz-se importante observar os fatos geradores das tradicionais espécies tributárias: taxas, contribuições de melhoria e impostos, de forma a vislumbrarlhe os princípios, aptos a racionalizarem a carga tributária. Neste ponto, observa-se

${ }^{1}$ Sacha Calmon Navarro Coelho. Comentários à constituição de 1988; sistema tributário. Rio de Janeiro: Forense, 1988, p 34 e 35. 
que as taxas e as contribuições de melhoria enquadram-se no grupo dos tributos com fatos geradores vinculados; ou seja, que trazem na hipótese de incidência a descrição de uma atuação pública.

Entretanto, diferenciam-se os fatos geradores das taxas e das contribuições de melhoria em razão, fundamentalmente, da natureza geral ou individual da atividade estatal: na taxa, o fato gerador é a prestação do serviço público ou o exercício do poder de polícia, dirigidos, específica e individualmente, ao contribuinte - a atividade administrativa nasce direcionada ao particular. Já na contribuição de melhoria, a hipótese legal consiste na obra pública, inicialmente voltada a toda coletividade, mas que termina por beneficiar, específica e individualmente, determinado contribuinte ${ }^{2}$.

Os dois fatos geradores acima descritos denotam uma relação de retribuição ao Estado, seja porque agiu, específica e individualmente, em função de determinado contribuinte, seja porque, mesmo ao atuar de forma geral, terminou por gerar benefícios particulares a alguém. Veja-se: a relação é de um sinalagma preciso, devendo quem ocasionou os gastos públicos específicos e divisíveis ou quem se beneficiou, singularmente, da máquina estatal, remunerar o Estado na medida dos dispêndios efetuados e dos benefícios auferidos; aqui, a tributação baseia-se pela equivalência.

Entretanto, além dos fatos geradores vinculados característicos das taxas e das contribuições de melhoria, tem-se os fatos geradores não vinculados, característicos dos impostos. Nestes, não se paga tributo para remunerar o Estado, mas para custear os seus gastos gerais; de outra sorte, não é qualquer pessoa que deve ser chamada para o custeio geral do Estado, mas as que têm capacidade contributiva. Eis a razão de a hipótese de incidência do imposto ser a descrição de um ato ou de uma situação jurídica titularizada pelo particular, de conteúdo econômico; apenas desta forma, podese verificar a existência e a medida da capacidade contributiva.

O fato é que não mais assumindo a tributação o caráter de remuneração ao Estado por atuações ou benefícios específicos, o custeio estatal deve ser feito na medida da aptidão econômica do contribuinte - o que é uma conseqüência dos direitos fundamentais. Aqui, melhor explica-se: os direitos fundamentais são intangíveis, mesmo aos deveres sociais. Desta forma, o dever social de custear os gastos públicos é incompatível com prejuízos ao núcleo essencial das liberdades individuais e ao mínimo existencial, significando tudo isto que apenas existe a aptidão econômica para o custeio do Estado, na medida em que ele compatibiliza-se com o exercício dos direitos fundamentais e com os princípios da ordem econômica, dando-se na exata medida das forças de cada qual.

Insta ainda afirmar, o que será explorado adiante, que a tributação na medida da capacidade contributiva realiza a igualdade e a neutralidade tributária na livre

${ }^{2}$ Geraldo Ataliba. Hipótese de incidência tributária. São Paulo: Malheiros, 1996, p.130. 
concorrência, d'onde se deduz que a capacidade contributiva decorre dos direitos fundamentais e dos princípios constitucionais basilares, manifestando-se como condição para a tributação não vinculada; eis o motivo pelo qual alguns doutrinadores chegam a afirmar que ela é a causa da tributação.

Em suma, os impostos implicam um modelo de custeio estatal de caráter contributivo, fundado na solidariedade e na capacidade contributiva - o que está expresso no Parágrafo Primeiro, art. 145, CF.

\section{MODELOS DE TRIBUTAÇÃo}

Não se pode deixar de alertar para o fato de no liberalismo ter-se pretendido atribuir natureza sinalagmática à carga tributária; o tributo seria a remuneração ao Estado pela infra-estrutura possibilitada ao particular, para exercer as suas liberdades. Decerto que referida mentalidade é a mais adequada a um modelo estatal que não conhece o valor da solidariedade e os direitos de cunho sociais. Por outro lado, há doutrina que insiste em resgatar o caráter sinalagmático da tributação, não apenas como fundamento valorativo, mas como modelo preferencial do custeio estatal.

Juan Manuel Barquero Estevan ${ }^{3}$ traz a notícia de que alguns autores vêm apresentando, como modelo tributário justo, aquele que se respalda, preferencialmente, nos tributos de caráter sinalagmático ou retributivo. Mediante o colacionado pelo autor, há entendimentos de que a tributação, nestes moldes praticada, seria a mais justa e apropriada aos imperativos da democracia, à medida que o Estado ver-se-ia custeado por quem the demanda as atuações. Desta forma, possibilitar-se-ia um maior controle dos gastos públicos e legitimar-se-ia a atuação estatal, presenciando, os contribuintes, as atividades públicas que custeiam; sem mencionar que o Estado se aproximaria daqueles que, efetivamente, lhe sustentam. Em outros termos, aproximaria a tributação por retribuição o Estado do contribuinte.

Talvez, a redescoberta de uma exação baseada, preferencialmente, na tributação por retribuição se justifique na elevada carga tributária estipulada em alguns países europeus, que se volta ao sustento de um Estado, largamente, assistencialista. Há até quem observe que referidos Estados tiram a iniciativa e a responsabilidade do indivíduo. É possível, pois, aparentar a alguns, que a alta tributação nestes termos realizada é desnecessária, obstando a economia privada em prol de um paternalismo estatal sem fundamentos e consistência. Daí o prestígio das propostas para um novo modelo de tributação: um Estado que aja dentro das preferências de quem paga pela sua atuação.

No entanto, críticas das mais variadas ordens - tanto principiológicas, como práticas-, desautorizam o modelo proposto: ter-se-ia um Estado mercantil, que agiria por quem está

3 Juan Manuel Barquero Estevan. La función Del tributo en el estado social y democrático de derecho. Madri: Centro de estudios políticos y constitucionales, 2002, pp. 89 a 106. 
disposto e possui condições para pagar pelas suas atuações. Desta forma, não haveria razões práticas para afastar-se a esfera de atuação pública da privada ${ }^{4}$; se as atividades estatais passam a justificar-se na retribuição, por óbvio que o mercado é que se apresenta como o instrumento adequado para atuações de tal jaez.

Fato é que a proliferação da tributação sinalagmática perpetuariaum estado de compra das atuações estatais; inclusive das necessárias ao gozo das liberdades individuais - ter-seia de pagar pelo uso de um espaço público? Ou pela atuação específica da polícia, que debelou a invasão de terceiros à propriedade? Ou pela atividade de bombeiros, que retirou o indivíduo dos escombros de um automóvel? Ou pelo exercício do direito do voto? Tais situações, não é exagero afirmar, transmudaria o conceito de direito fundamental em dever de pagar pelas atuações estatais que lhes são necessárias, o que infligiria forte golpe à legitimidade da atuação Estatal; eis o que resulta de um Estado mercantil.

De outra sorte, o caráter democrático, de referido modelo, tende a desnaturarse, uma vez que a atuação pública em consonância com as preferências dos cidadãos iria delimitar-se pela possibilidade do pagamento, de forma que o Estado dirigir-se-ia para quem poderia e desejaria, por ele, pagar. Ainda importa mencionar um outro elemento, prejudicial à democracia: a larga tributação sinalagmática restringiria as liberdades de escolha do indivíduo, à medida que o Estado lhe impusesse a atuação estatal e o respectivo custeio. Este é um problema que nem mesmo os defensores do sustento estatal por retribuição negam ${ }^{5}$, sendo uma observação tanto mais grave quanto o Estado não se abstém de utilizar tributos com tais características.

Insta, por fim, lembrar o óbvio: à medida que a sociedade torna-se complexa, as atuações, imprescindíveis à existência de uma mínima ordem social indispensável ao convívio harmônico, tornam-se cada vez mais variadas: o controle do meio ambiente, a fiscalização da ordem econômica, a regulação do consumo, por exemplo. Tudo isto significa que as considerações relativas à igualdade e ao pluralismo em uma democracia exigem intervenções estatais das mais diversas índoles para serem suportadas, preferencialmente, por tributos sinalagmáticos, respaldados no princípio da equivalência.

Trocando em miúdos: o Estado, longe de atuações pontuais, vê-se diante uma complexa teia de atribuições, insusceptíveis de serem custeadas por tributação sinalagmática: a) seja em virtude de uma série de atividades indivisíveis ou voltadas aos hipossuficientes; b) seja porque a tributação, preferencialmente por retribuição, levaria a um permanente estado de compra das atuações públicas imprescindíveis às liberdades; c) seja em razão do risco de restrições inadmissíveis à liberdade do indivíduo. Por tudo isto, o justo, o razoável e o possível refletem-se no modelo de tributação respaldado na tributação contributiva, fundada no dever do indivíduo de custeio geral do Estado, independente de atuações específicas e benefícios particulares. O sustento do Estado

\footnotetext{
${ }^{4}$ Juan Manuel Barquero Estevan, op. cit., p. 117.

5 Juan Manuel Barquero Estevan, op. cit., p. 126
} 
deve, portanto, realizar-se, preferencialmente, por tributos com fatos geradores próprios dos impostos, que refletem a relação de custeio geral baseada na solidariedade e na capacidade contributiva ${ }^{6}$.

\section{F- A CONTRIBUIÇÃO COMO MODELO DE TRIBUTAÇÃO}

Entretanto, dentre a tributação por equivalência realizada pelas taxas e contribuições de melhoria e a tributação contributiva efetuada pelos impostos, surge a tributação pela contribuição, podendo-se questionar se ela apresenta caráter sinalagmático, contributivo ou misto.

Neste ponto, inicia-se pela observação de que a contribuição ora justifica-se na eficiência do custeio das atuações públicas, ora explica-se na igualdade da carga tributária, ora fundamenta-se em razões não tão nobres, como à consistente na maior retenção de recursos tributários nas mãos da União Federal, que não rateia as contribuições com os demais entes federados. Uma outra razão também pode ser enumerada para a proliferação das contribuições: o fato de o judiciário ter-lhe negado a aplicação de princípios limitativos ao poder de tributar, sob a justificativa de que eles se reportam aos impostos e não às contribuições, que são espécies tributárias autônomas e distintas daqueles.

Mas o fato é que as contribuições têm-se tornado cada vez mais freqüentes, de forma a ser necessária a definição da sua função na tributação. Em relação ao ordenamento jurídico brasileiro, dentro do modelo conferido ao Brasil como Estado Democrático e Social de Direito, assoberbado de funções da mais variada índole proteção às liberdades individuais, promoção dos direitos sociais relativos à dignidade humana, realização dos interesses difusos, ordem interna e externa - não existe dúvida de que a tributação é, preferencialmente, contributiva, realizada por tributos com fatos geradores próprios dos impostos.

Desta forma, a contribuição não pode deformar o caráter de custeio estatal por tributos, preferencialmente, contributivos. Entretanto, permanecendo a estudar o ordenamento jurídico brasileiro, constata-se o já assente na doutrina: o constituinte, quando prevê a competência tributária para a criação das contribuições, não raro, esquiva-se de traçar-lhe o fato gerador. Por outro lado, referente aos casos em que o constituinte trabalhou a regra-matriz de incidência tributária das contribuições, tem-se tanto a utilização de fatos geradores vinculados como a de fatos geradores não vinculados. Como exemplo, pode-se mencionar a contribuição para a seguridade social incidente sobre o lucro líquido do empregador, que apresenta fato gerador não vinculado,

\footnotetext{
${ }^{6}$ Sobre o conceito de estado fiscal, o sustentado, prioritariamente, por impostos, ver José Casalta Nabais. Por um estado fiscal suportável. Estudos de direito fiscal. Coimbra: Almedina, 2005, cap. I.
} 
consistente na manifestação de capacidade contributiva análoga à do IR; já a contribuição para a seguridade social incidente sobre o empregado apresenta fato gerador vinculado aos benefícios previdenciários, voltados, específica e individualmente, ao contribuinte.

Eis a razão de afirmar-se que o fato gerador das contribuições pode ser vinculado e não vinculado, de forma a sobressair o caráter de retribuição ou contributivo da contribuição. Dentro desta maleabilidade, que resulta do silêncio do texto constitucional, há doutrina que entende que a contribuição, para além do fato gerador, se caracteriza pelo caráter sinalagmático - ela deve ser prestada por quem participa do grupo que será o destinatário da atuação pública custeada pelos recursos da contribuição ${ }^{7}$. Dentro desta perspectiva, mesmo aquelas contribuições de fato gerador não vinculado têm, efetivamente, caráter remuneratório; nos limites da capacidade contributiva, uma pessoa será chamada a arcar com determinados gastos em razão de integrar o grupo a ser beneficiado pela atuação pública custeada com as receitas decorrentes da tributação específica.

Face, ainda, ao necessário caráter sinalagmático da contribuição - manifesto na adequação -, há opiniões no sentido de ser possível o seu custeio através de um cálculo per capita entre os integrantes do grupo ao qual se volta a atuação estatal, custeada pela contribuição ${ }^{8}$. Pensa-se, entretanto, ser esta posição inadmissível, sob pena de ferimento aos direitos fundamentais. Destarte, a tributação, quando perde o caráter de remuneração pelas atuações públicas dirigidas ao contribuinte ou que lhes geram benefícios particulares, passa a ser respaldada na capacidade contributiva, de forma que a imposição tributária ocorra na medida da aptidão econômica de cada qual. Evita-se, de tal feita, que os direitos fundamentais sejam consumidos pela tributação e que lhe seja retirada o caráter da individualidade.

A necessária tributação na medida da capacidade contributiva, quando não mais se está a tratar da remuneração pela atuação e benefícios a favor do contribuinte, tem um outro aspecto de suma relevância: a neutralidade tributária na livre concorrência.

\footnotetext{
7 Marco Aurélio Greco leciona: "Atendido o requisito da necessidade, cumpre verificar o requisito da adequação no sentido de aferir-se se aquele determinado fenômeno captado pela lei, para deflagrar o dever de pagar a contribuição, é funcionalmente adequado para a obtenção do fim e substancialmente adequado para não agredir outro valor protegido constitucionalmente. Neste plano, é pertinente verificar se o fenômeno captado pela contribuição está em sintonia com a finalidade. Uma contribuição que defina como fato determinante do dever de pagar algo que não tem nenhuma relação com a finalidade que justifica sua instituição fere a norma de validação constitucional por desatender ao requisito da adequação" (Aut. cit. Contribuições. Uma figura sui generis. São Paulo: Dialética, 2000, p. 142). Na página seguinte, prossegue: "Assim, uma contribuição de intervenção no domínio econômico deve captar, para fins de exigência, algum evento, realidade, pessoa ou situação que esteja relacionado com a intervenção em si mesma considerada".

${ }^{8}$ Neste sentido, manifesta-se Marco Aurélio Greco: “... Assim não repugna que certas contribuições adotem como critério um rateio per capita (tipo poll tax); também não repugna que certas contribuições que, de algum modo suponham o número de horas de trabalho, possam ser dimensionadas em valores fixos por hora trabalhada, e assim por diante" (aut. e op. cit., p. 197).
} 
Destarte, quando a tributação se volta ao custeio de despesas que não sejam específicas e divisíveis, ela deve afligir o contribuinte na medida das suas forças, onerando de forma equivalente os que apresentam igual aptidão para contribuir com os gastos públicos. Apenas desta forma, a tributação não será elemento que intervenha na concorrência, beneficiando determinadas atividades e contribuintes em detrimento de outras atividades e de outros contribuintes, à medida que impõe encargos financeiros que pesem mais a uns do que aos outros.

Resta ainda asseverar que mesmo em matéria de taxas, na qual há relação de estrita remuneração, o Supremo Tribunal Federal ${ }^{9}$ tem admitindo que elementos da capacidade contributiva componham a base de cálculo, de forma que a tributação por remuneração não inviabilize os direitos fundamentais do contribuinte. Ora, se a capacidade contributiva manifesta-se até nas taxas, como pode ser afastada no caso das contribuições, quando se está custeando os gastos gerais referentes à determinada atuação? O que assentou o Supremo Tribunal Federal foi a onipresença da capacidade contributiva, que mesmo numa relação de equivalência entre a atuação estatal e o indivíduo, não é afastada.

Eis, em breve síntese, a razão pela qual se entende que afora a remuneração por ações estatais de caráter individual, o custeio estatal deve ser feito na estrita medida de capacidade contributiva, o que viabiliza a tributação justa, pessoal, em respeito aos direitos fundamentais e aos cânones da ordem econômica. Nesta ordem de consideração, entendese que os arts. $4^{\circ}$. e $5^{\circ}$. do CTN, antes de tratarem das espécies tributárias, assentam que os fatos geradores viáveis aos tributos são os característicos da taxas, das contribuições de melhoria e dos impostos. Deles, que delineiam ou a relação de custeio fundada na remuneração por atuações e benefícios específicos e individuais ou a relação de custeio geral, na medida da capacidade contributiva, não pode fugir a contribuição. Assenta-se, portanto: o fato gerador da contribuição não apresenta peculiaridades referentes aos fatos geradores das tradicionais espécies tributárias.

Mas aqui, resta indagar sobre o necessário caráter sinalagmático das contribuições, no que ajuda a análise do texto constitucional; mais especificamente, dos dispositivos referentes às contribuições para a seguridade social. Vê-se que a seguridade social possui contribuições específicas do empregador e do empregado, ambos beneficiados pela atuação do Estado na área da seguridade; em especial, na área da previdência.

9 Consta do Acórdão da ADI 453/SP, Rel. Min. Gilmar Mendes: ““...O critério adotado pelo legislador para a cobrança dessa taxa de polícia busca realizar o princípio constitucional da capacidade contributiva, também aplicável a essa modalidade de tributo, notadamente quando a taxa tem, como fato gerador, o exercício do poder de polícia....". Concluindo o Voto: "No caso da taxa de físcalização da CVM a variação dos valores lançados não só reflete a capacidade contributiva do interessado, bem como espelha a quantidade necessária do serviço público dispensado, uti singuli, e que deve ser remunerado na exata proporção da trabalho da fiscalização efetivado. Conclusivamente, Senhora Presidente, voto pela improcedência dessa Ação Direta de Inconstitucionalidade”. 
Os empregados são os beneficiários diretos da previdência social, tanto que as suas contribuições têm fato gerador característico das taxas. Já os empregadores beneficiamse, indiretamente, da previdência; consumindo-se a capacidade laborativa dos empregados em benefício dos empregadores, é justo que arquem com os dispêndios relativos ao desgasto físico e moral decorrente do trabalho. Poder-se-ia até assentar que a previdência seria dever originário dos empregadores, que é entregue ao Estado face à impossibilidade daqueles de arcarem com os ônus previdenciários; em contrapartida, são chamados a colaborar, especificamente, com a seguridade.

$\mathrm{Na}$ análise, entretanto, de outras contribuições para a seguridade social, verificase inexistir qualquer vínculo especial entre o contribuinte e o beneficiário da atuação pública, na qual é vertida a contribuição; é o caso da CPMF. Entretanto, é fato que esta contribuição encontra-se dispersa por toda a sociedade, sem agravar, em especial, determinado grupo ou segmento. Desta forma, pensa-se que a situação de dispensa da adequação entre o contribuinte e o grupo beneficiado pela atuação estatal apenas fazse possível quando não há a estipulação de ônus a um grupo específico de contribuintes; ou seja, quando a contribuição é suportada por toda a coletividade - caso em que, a rigor, o Prof. Ricardo Lobo Torres nega a existência de contribuição, falando de imposto com destinação especial ${ }^{10}$. Neste tocante, é interessante o estudo da igualdade no custeio do Estado.

\section{(i) A igualdade no CUSTeio do estado}

A igualdade no custeio do Estado não pode ser obtida pela utilização de apenas um critério de distribuição da carga tributária, mas pela conjugação de vários - tanto que se têm diferentes modelos de tributação.

$\mathrm{Na}$ tributação por equivalência, na qual se retribui o Estado por atuações específicas ou que geram benefícios particulares, a igualdade se realiza pela perspectiva da remuneração. Em outras palavras, não é justo que toda a coletividade arque com as atuações em prol de determinado contribuinte ou que termine por gerar-lhe benefícios individuais; de forma que nestes casos, ele é que deverá custear a atuação do Estado.

Entretanto, é certo que a imposição da tributação sinalagmática apenas deve ser implementada quando ela não inviabiliza os direitos fundamentais. Como exemplo, pode-se falar da assistência judiciária - matéria constitucional e legal -, na qual se dispensa dos pagamentos das custas judiciais as pessoas que não possam efetuá-lo; caso não previsto referido benefício fiscal, haveria negativa do acesso ao judiciário, $\mathrm{o}$ que resultaria em impedimento à fruição de garantia fundamental prevista no art. $5^{\circ}$., da

${ }^{10}$ Ricardo Lobo Torres. Aspectos fundamentais e finalísticos do tributo. In $\mathrm{O}$ tributo; reflexão multidisciplinar sobre sua natureza. Ives Gandra da Silva Martins (org). Rio de Janeiro: Forense, 2007, p. 46. 
Constituição Federal. Sem mencionar que a vedação ao judiciário deixa ao desabrigo os direitos do cidadão, que em ambiente de litígio ou mesmo de não litígio dependem da manifestação dos juízos para se realizarem.

Mas aqui, fica assinalado este primeiro método de realização da igualdade em matéria de custeio do Estado: aquele que demanda atuações individuais ou que se beneficia especificamente da máquina administrativa deve arcar com os respectivos custos. No entanto, falou-se que, preferencialmente, o modelo de custeio do Estado é realizado pela tributação contributiva, em que os gastos do Estado são suportados por toda a coletividade, na medida da capacidade contributiva de cada contribuinte. E as razões de ordem prática e principiológicas, que levam à prevalência da tributação contributiva em relação à sinalagmática, já foram tratadas neste estudo: liberdade, solidariedade, legitimidade democrática da atuação estatal.

É chegado, pois, o momento de afirmar-se: a capacidade contributiva é o critério preferencial a ser utilizado para a distribuição isonômica da carga tributária entre a população. Ou seja, na medida da capacidade contributiva, as pessoas custearão os gastos públicos gerais, de forma que iguais manifestações de capacidade contributiva sejam tributadas igualmente e que desiguais manifestações de capacidade contributiva sejam tributadas desigualmente.

Desta forma, tem-se que a igualdade em matéria de custeio do Estado faz-se da seguinte forma: os destinatários das atuações públicas individuais e específicas ou os beneficiados, particularmente, por atuações públicas gerais deverão remunerar o Estado no limite do custo da atuação e do valor do benefício; a remuneração implica, entretanto, critério residual de distribuição da carga tributária. A regra é que os gastos do Estado sejam suportados por toda a coletividade, na medida da capacidade contributiva de cada qual. Em palavras mais sintéticas, pode-se asseverar: residualmente, o Estado é custeado por remunerações a atuações e benefícios pontuais; mas a regra geral é a de que a distribuição dos encargos de custeio do Estado faça-se pela capacidade contributiva.

Ocorre que em certas ocasiões é possível o amálgama entre os critérios da remuneração e da capacidade contributiva, o que ocorre na contribuição de fatos geradores não vinculados, que tem as receitas direcionadas ao custeio de respectivo órgão, entidade ou despesa. Neste ponto, deve-se ter uma das duas situações: a) ou a contribuição incide sobre manifestação de capacidade contributiva dispersa por toda a coletividade, de forma que a capacidade contributiva de um não seja mais onerada do que a capacidade contributiva de outro - o que ocorre no caso da CPMF; b) ou a capacidade contributiva especificamente onerada apresenta vínculos com a atuação custeada pela contribuição, de forma a poder-se justificar a maior oneração de determinado grupo ou segmento em relação ao restante da coletividade - eis o caso em que a tributação apresenta um caráter misto, sinalagmático e contributivo.

Neste ponto, a adequação surge como um elemento indispensável à realização da igualdade em matéria tributária: se determinada pessoa, de alguma forma, mesmo como mero integrante de uma categoria, tem ligação com a atuação custeada pela 
contribuição, ela encontra-se passível de ser chamada para contribuir com a respectiva atuação estatal, na medida da sua capacidade contributiva. É este, inclusive, o viés pelo qual se deve fazer uma análise referente à constitucionalidade da contribuição do aposentado para a previdência.

Tendo-se assentado, após a emenda constitucional n. 40, que a contribuição do aposentado não apresenta natureza sinalagmática e fato gerador próprio das taxas, antes manifestando caráter contributivo, a questão encontra-se em saber se a tributação, nestes termos realizada, faz-se possível, de forma a não se ferir a isonomia, que é cláusula pétrea insusceptível de ser excepcionada por emenda. Num primeiro momento, urge verificar que os trabalhadores inativos passam a serem afligidos de forma mais intensa, em sua capacidade contributiva, do que os outros grupos e segmentos sociais, devendo-se questionar se há adequação que justifique o maior encargo que lhes foi atribuído, em razão do custeio da previdência dos servidores públicos.

O fato é que a contribuição sobre o trabalhador justifica-se não no aspecto de solidariedade com os demais trabalhadores ou no caráter contributivo, mas na perspectiva da remuneração; tanto é assim que referida contribuição tem fato gerador próprio da taxa - está-se a retribuir ao Estado os benefícios previdenciários percebidos ou a perceber. De outra sorte, é expressa a Constituição ao referir-se que os grupos, especialmente, onerados por contribuições para a seguridade social são os empregados - em caráter, estritamente, sinalagmático - e os empregadores - em caráter misto, sinalagmático e contributivo; fora estes, a seguridade social deverá ser custeada por toda a coletividade, sendo um dos seus princípios a eqüidade na forma de participação do custeio - art. 194, parágrafo único, IV.

Referida sistemática de custeio leva à conclusão de que a única espécie de tributação, apta a justificar a sujeição dos empregados ao custeio da seguridade, é a de caráter remuneratório, não havendo adequação entre os trabalhadores inativos e a seguridade que justifique a imposição de contribuições àquele para o custeio desta; $\mathrm{e}$ referida observação não passou desapercebida por Maria Sylvia Zanella de Pietro ${ }^{11}$. Por outro lado, é certo que os princípios da seguridade social são aplicados à previdência dos servidores públicos - parágrafo 12, art. 40, CF -, o que possibilita a aplicação das conclusões acerca das possíveis modalidades de tributação relativas à previdência geral à previdência dos servidores estatutários.

É fundamental, pois, o exame da existência de adequação que permita a maior oneração da capacidade contributiva de determinado grupo para o custeio de

11 “.... É estranho e contraditório afirmar que o regime deve ser custeado por toda a sociedade e, com base no princípio da solidariedade, defender a contribuição dos inativos e pensionistas, que correspondem a apenas uma pequena parcela da sociedade. A contribuição de toda a sociedade é representada pela receita pública proveniente de impostos" (Maria Sylvia Zanella di Pietro. Direito Administrativo. São Paulo: Atlas, 2005, p. 514). 
determinada atividade ou entidade, de maneira que seja resguarda a igualdade no custeio dos gastos públicos.

\section{A ADEQUAÇÃo DA CONTRIBUIÇÃO AO JUSTO MODELO DE CUSTEIO DO ESTADO}

Há, pois, um modelo de tributação que reflete a justiça no custeio dos gastos públicos, dentro do Modelo em que é constituído o Estado Democrático e Social brasileiro: uma tributação, predominante, contributiva, baseada na capacidade contributiva, na qual se assegura o equilíbrio entre liberdades individuais e deveres sociais e a distribuição equânime da carga tributária. As contribuições não podem descaracterizar referido modelo, não se devendo interpretar os silêncios constitucionais como cheque em branco ao legislador; antes, tem-se de estruturar as contribuições de forma a adequá-las ao modelo justo e equânime do custeio dos gastos públicos.

Assevera-se, pois, uma primeira conclusão: não deve haver a proliferação exacerbada das contribuições, sob pena da descaracterização do caráter contributivo do custeio estatal. Ainda vale lembrar que o incremento das contribuições traz ao cenário tributário brasileiro os problemas decorrentes de uma expressiva tributação sinalagmática, como a permanente situação de compra, pelo particular, das atuações do Estado que sejam necessárias à fruição das liberdades individuais. E esta situação, para além dos problemas referentes à legitimidade da atuação do Estado, na qual os direitos fundamentais transmudam-se em deveres de compra das atuações públicas que lhes são essenciais, põe em cheque a autonomia das escolhas.

De certo que a imposição tributária justificada nas atuações do Estado sobre a pessoa ou o grupo da qual ela participa vai minando as livres escolhas do indivíduo - à medida que ele vai sendo mais onerado em razão dos grupos que integra ou das atividades que pratica, a tributação funciona como mecanismo de desestímulo ou estímulo a escolhas que deveriam limitar-se ao livre arbítrio de cada qual. Ademais, a tributação, nestes moldes, pode chegar a inviabilizar as opções do indivíduo. Ainda, nesta ordem de consideração, insiste-se em que o custeio obrigatório pelo particular das atuações estatais que lhe são impostas ou ao grupo a que pertence, leva a uma situação de substituição de escolhas, do particular pelo Estado; ao invés de o primeiro decidir acerca de como locar os seus recursos e estruturar o ambiente no qual atua, o Estado passa a intervir na economia, nas atividades sociais e de cunho associativo, impondo ao indivíduo a sujeição às atividades que julga necessárias, bem como o respectivo custeio.

Na esteira do dito acima, verifica-se a situação da previdência: ela não se limita a assegurar o mínimo indispensável a uma vida digna, impondo uma relação atuarial em que o benefício equivalerá a média de $80 \%$ (oitenta) dos mais elevados salários de contribuição, que alcançam, nos casos dos servidores públicos, a totalidade da remuneração. Veja-se que o Estado impõe ao particular que ele contribua para a sua 
previdência tendo por limite da contribuição e por perspectiva do benefício o total da remuneração, o que implica a ingerência, para além da necessidade, do poder público na vida econômica e privada do contribuinte: aquele o obriga a se precaver, face aos eventos futuros de incapacidade para o trabalho, no limite das suas forças, estipulando o método único a ser utilizado - a previdência oficial. E isto, retira do contribuinte a liberdade de utilizar os mecanismos que ele venha a julgar mais convenientes para suportar as intempéries dos tempos vindouros: poupança, investimento em ações e títulos mobiliários, aquisição de imóveis, obras de arte ou ouro, participação em fundos e sociedades, etc. Sem falar da liberdade do cidadão de não pretender manter, no futuro, o mesmo padrão de vida que possui, no presente; a forma de como viver é inalienável em qualquer democracia!

Desta maneira, não se pode furtar à afirmativa: a criação da contribuição, quando significa a imposição pelo Estado ao contribuinte da fruição de determinado serviço público a ser por ele custeado, deve respaldar-se nos estritos limites da proporcionalidade: necessidade, adequação e vedação ao excesso. A introdução específica do princípio da proporcionalidade à análise da contribuição foi efetuada pelo professor Marco Aurélio Greco, em obra já mencionada neste artigo: Contribuição. Uma figura sui generis. Entretanto, calha a análise da proporcionalidade pelo ângulo dos limites das intervenções públicas na esfera da liberdade do indivíduo, de formaconsonante o já mencionado - que o Estado não substitua o particular nas suas decisões e escolhas. A tributação por contribuição que demonstre o referido perfil deve, portanto, justificar-se no estritamente necessário ao Estado para que ele assegure as liberdades individuais, o mínimo vital e os interesses difusos esparsos pelo texto constitucional. Nesta ordem de considerações, percebe-se com facilidade: pode o Estado, sem problemas referentes à autonomia privada, impor contribuição a um órgão oficial de previdência, no limite necessário a assegurar a dignidade material futura - vez que cabe ao Estado a tutela do mínimo existencial. Entretanto, não há como se deixar de perceber a violação à liberdade na imposição de contribuição previdenciária no limite superior ao que seria necessário à garantia do básico, já que, nesta situação, não se está perante a susceptibilidade à tutela das políticas e atuações públicas; antes, está-se em área reservada, estritamente, às opções de cada qual.

Há ainda um último e sério problema: o fato de as contribuições serem regulamentadas, constitucionalmente, pela finalidade, não pode levar ao desprezo do fato gerador, sob pena de prejudicar o justo modelo de custeio do Estado. Conforme o já assente, os fatos geradores refletem a relação de custeio entre o contribuinte e o Estado, trazendo consigo a necessária aplicação dos princípios e regras decorrentes do modelo adotado. Nos tributos com fatos geradores vinculados, nos quais há uma relação de remuneração, a tributação dá-se pela equivalência, numa dinâmica sinalagmática que norteia o regime jurídico a ser aplicado. Por outro lado, nos tributos de fatos geradores não vinculados, a relação é contributiva, baseada na capacidade contributiva, de forma que as regras e os princípios dela decorrentes devem ser obser- 
vados em todo e qualquer tributo de fato gerador não vinculado, mesmo quando se estiver tratando de uma contribuição.

Desta forma, as decisões que restringem a imunidade à espécie tributária em relação à qual ela é prevista no texto constitucional não consiste na melhor decisão do conflito. Tem-se de averiguar se a imunidade decorre da capacidade contributiva; caso afirmativo, ela deve ser aplicada a todos os tributos de fatos geradores não vinculados, sob pena de a tributação desestabilizar o equilíbrio entre liberdades individuais e o dever social de custeio do Estado, que se perfaz na tributação mediante a capacidade contributiva.

Os exemplos avultam-se, restando ainda alertar: o princípio de solidariedade em matéria de contribuições, mais especificamente em matéria de contribuições para a seguridade social, não permite desconsiderar os direitos fundamentais e os princípios constitucionais basilares, como o da igualdade e os referentes à estruturação da ordem econômica. A solidariedade social é um interesse basilar do ordenamento jurídico, que convive ao lado de outros elementos, igualmente, basilares, de forma a ter-se de construir uma relação de equilíbrio e não de subordinação.

Poder-se-ia até dizer que a tributação contributiva apresenta caráter solidário, vez que voltada ao custeio de complexas atuações do Estado, que não mais se limitam ao imprescindível à ordem, abrangendo funções referentes à dignidade humana e à democracia social. Mas a solidariedade em matéria de contribuições implica um plus: ela funciona como fundamento ao fato de estar-se direcionando receitas, auferidas de toda a sociedade, a órgão ou à entidade destinados às atuações específicas - ainda mais, se as atuações consistem na tríade que compõe a seguridade: saúde, previdência e assistência. Entretanto, em nenhum momento, a solidariedade social autoriza a desconsideração dos princípios e regras necessários ao justo modelo de custeio estatal - o que exige, conforme já ressaltado, uma tributação baseada, predominantemente, na capacidade contributiva, que representa e concretiza o imprescindível equilíbrio entre os princípios basilares e fundamentais do ordenamento jurídico constitucional brasileiro.

\section{i TóPICOS CONCLUSIVOS}

Diante do acima estipulado, conclui-se nos seguintes termos:

I. Atualmente, não mais vige dúvida de que perante a Constituição Federal de 1988 as contribuições apresentam natureza tributária, entendendo segmento doutrinário e o STF que são espécie tributária autônoma;

II. Os viáveis fatos geradores em matéria tributária são os característicos dos impostos, das taxas e das contribuições de melhoria, deles não podendo fugir as contribuições;

III. Aplicam-se às contribuições os princípios inerentes ao fato gerador que possuem; desta forma, o regime jurídico decorrente do fato gerador não 
vinculado não pode ser esquecido e superado em razão da finalidade da contribuição, quando ela tem fato gerador próprio do imposto;

IV. O modelo tributário justo e racional, posto que em consonância com as liberdades fundamentais, a ordem econômica, a igualdade na distribuição da carga tributária e a legitimidade democrática da atuação estatal, é aquele que apresenta caráter, predominantemente, contributivo, com respaldo na capacidade contributiva e na solidadariedade. Desta feita, a tributação por contribuição não pode atribuir feição, marcadamente, sinalagmática à tributação, perpetuando um estado de compra do Estado pelo Particular e de substituição das escolhas da iniciativa privada pelo ente público.

\title{
BibliografiA
}

Ataliba, Geraldo. Hipótese de incidência tributária. São Paulo: Malheiros, 1996.

Coêlho, Sacha Calmon. Comentários à constituição de 1988; sistema tributário. Rio de Janeiro: Forense, 1988.

Di Pietro, Maria Sylvia Zanella. Direito administrativo. São Paulo: Atlas, 2005.

Estevan, Juan Manuel Barquero. La función del tributo en el estado social y democrático de derecho. Madri: Centro de estudios políticos y constitucionales, 2002.

Greco, Marco Aurélio. Contribuições. Uma figura sui generis. São Paulo: Dialética, 2000.

Nabais, José Casalta. Por um estado fiscal suportável. Estudos de direito fiscal. Coimbra: Almedina, 2005.

Torres, Ricardo Lobo. Aspectos fundamentais e finalísticos do tributo. In $\mathrm{O}$ tributo; reflexão multidisciplinar sobre sua natureza. Ives Gandra da Silva Martins (org). Rio de Janeiro: Forense, 2007.

\section{CONTRIBUTIONS AND TRIBUTARY JUSTICE IN BRAZIL'S JURIDICAL ORDER}

\begin{abstract}
The present article is about contributions - tax's species - in Brazilian law. The study focuses initial discussions about contributions, in special treating of their nature - if it is a tribute and if there exists a tribute's autonomy specie. The study emphasizes the compatibility between taxation for contributions with the Brazilian constitutional system. It draws the rational and equity taxation model, in conformity with democracy, fundamental liberties, economic order and isonomy. Lastly, it proposes ways for the creation and regulation of contribution, in order to sustain its compatibility with this taxation model in Brazil.
\end{abstract}

Key words: Taxation. Contribution. Brazilian law. 